\title{
VARIABILIDADE ESPACIAL E TEMPORAL DA PRECIPITAÇÃO PLUVIAL NA BACIA HIDROGRÁFICA DO RIBEIRÃO JOÃO LEIŢE-GO ${ }^{1}$
}

\section{EDUARDO H. M. DOS SANTOS ${ }^{2}$, NORI P. GRIEBELER ${ }^{3}$, LUIZ F. C. DE OLIVEIRA ${ }^{4}$}

RESUMO: A precipitação pluvial constitui-se na principal variável hidrológica de entrada do ciclo hidrológico e para conhecimento da variabilidade espacial e temporal como informação básica para estudos hidrológicos, manejo de bacias hidrográficas, gestão de recursos hídricos, dentre outros. Os recursos hídricos superficiais produzidos nessa bacia são essenciais ao desenvolvimento do eixo Goiânia-Anápolis-Brasília e, recentemente, com o aumento da demanda hídrica, tem sido relatados conflitos pelo uso da água. Dessa maneira, tem-se que o desenvolvimento de estudos hidrológicos visando ao melhor entendimento e aproveitamento dos recursos hídricos é estratégico para o desenvolvimento da região. Nesse sentido, objetivou-se com este estudo mapear a precipitação média mensal e anual na bacia hidrográfica do Ribeirão João Leite, com o auxílio de técnicas geoestatísticas. Foram avaliados os modelos de semivariograma esférico, exponencial e gaussiano, ajustados pelo método dos mínimos quadrados ponderados, sendo que o modelo utilizado no mapeamento por krigagem foi o que apresentou o menor erro médio indicado pela validação cruzada. Foi constatado bom desempenho das técnicas geoestatísticas no mapeamento da precipitação média mensal e anual, indicado pelos pequenos erros encontrados, podendo-se destacar o modelo de semivariograma exponencial, que se sobressaiu na maioria dos eventos estudados.

PALAVRAS-CHAVE: geoestatística, meio ambiente, hidrologia.

\section{SPATIAL AND TEMPORAL BEHAVIOR OF PLUVIAL PRECIPITATION IN THE JOÃO LEITE WATERSHED, GO}

\begin{abstract}
The pluvial precipitation is the main hydrology variable input in the hydrological cycle and the knowledge of their spatial and temporal behavior is basic material for hydrological studies, watershed and water resource management, among others. The surface water produced in this basin is essential to the development of the Axis Anápolis-Goiânia-Brasília and recently, with the increasing of water demand, it has been reported conflicts by the water use. Thus, it appears that the development of hydrological studies aimed for better understanding and utilization of water resources are strategic for the development of the region. In this way, this work purpose to map the average monthly and annual precipitation in the João Leite watershed, using geostatistical techniques. It was evaluated the spherical, exponential and gaussian semivariogram models, adjusted by the weighted least squares method, being the model used for mapping by kriging the one that produced the lowest average error indicated by cross validation. It was found a good performance of geostatistical techniques in mapping the average monthly and annual precipitation, indicated by small errors, which can be highlighted the exponential model, with the best results in the most of the studied events.
\end{abstract}

KEYWORDS: geostatistics, environment, hydrology.

\section{INTRODUÇÃO}

A precipitação é um importante componente do ciclo hidrológico, sendo o fenômeno responsável pela entrada de água na bacia hidrográfica. Devido à sua capacidade de produzir escoamento superficial, a precipitação pluvial é considerada a forma de precipitação de maior

\footnotetext{
${ }^{1}$ Extraído da tese de doutorado do primeiro autor.

${ }^{2}$ Instituto Federal Goiano, Câmpus Urutaí - GO.

${ }^{3}$ Escola de Agronomia, UFG, Goiânia - GO.

${ }^{4}$ Departamento de Engenharia, UFLA, Lavras - MG.

Recebido pelo Conselho Editorial em: 13-2-2009

Aprovado pelo Conselho Editorial em: 4-1-2011
} 
importância em regiões tropicais e subtropicais (BERTONI \& TUCCI, 2001). Sua variação espacial é grande, sendo influenciada principalmente pela localização geográfica, altitude, distância de fontes de umidade, temperatura, direção e intensidade dos ventos.

No mapeamento dessa variável, tendo em vista que o processo de mensuração envolve coleta de informação discreta em estações pluviométricas, frequentemente são empregados métodos de interpolação espacial, com destaque ao inverso do quadrado da distância e às técnicas geoestatísticas. A qualidade dos mapas obtidos por interpolação espacial é altamente dependente da procedência dos dados que servirão de base, da representatividade das séries históricas e da distribuição espacial das estações pluviométricas (REIS et al., 2005).

$\mathrm{Na}$ análise de dados desenvolvida pela estatística clássica, considera-se que as realizações das variáveis aleatórias são independentes entre si, desconsiderando assim a influência entre observações vizinhas. Contudo, a precipitação e muitas outras variáveis climáticas apresentam estruturação nas variações vizinhas, o que caracteriza dependência espacial dos dados, e desta maneira, o emprego da geoestatística proporciona melhorias na qualidade final dos mapas (VIEIRA, 2000).

Recentemente, com o desenvolvimento e expansão dos sistemas de informações geográficas (SIG), é possível realizar a caracterização espaço-temporal de variáveis ambientais em grandes extensões territoriais, dentre as quais se destaca a precipitação pluvial. Nesse aspecto, estudos visando a checar a acurácia de diferentes métodos de interpolação espacial no mapeamento da precipitação, visando a fundamentar técnicas de elaboração de mapas-base para simulação hidrológica e gestão de recursos hídricos, constituem demanda hidrológica atual (CECÍLIO \& PRUSKI, 2003; JUNQUEIRA JÚNIOR et al., 2008; MONTEBELLER et al., 2007; SOUZA et al., 2005).

A bacia hidrográfica do Ribeirão João Leite apresenta área de $766,8 \mathrm{~km}^{2}$ e está localizada ao norte da capital do Estado de Goiás. Os recursos hídricos superficiais ali produzidos são os principais responsáveis pelo abastecimento urbano da cidade de Goiânia - GO, além de suprirem demandas por irrigação, piscicultura e outras atividades ao longo da bacia. Nos últimos anos, a demanda por água na bacia hidrográfica do Ribeirão João Leite tem superado sua disponibilidade hídrica, o que, conciliado à baixa qualidade da água presente em muitos períodos do ano, tem gerado conflitos entre usuários, evidenciando a necessidade de estudos hidrológicos visando a subsidiar ações pelos responsáveis pela gestão dos recursos hídricos.

Nesse contexto, o objetivo deste estudo foi mapear, por meio de técnicas geoestatísticas, a precipitação média mensal e anual na bacia hidrográfica do Ribeirão João Leite - GO, testando o ajuste dos modelos de semivariograma esférico, exponencial e gaussiano ajustados pela técnica dos mínimos quadrados ponderados.

\section{MATERIAL E MÉTODOS}

O presente estudo contempla a bacia hidrográfica do Ribeirão João Leite com seção de controle na estação fluviométrica Captação João Leite, mantida pela Companhia de Recursos Minerais de Goiás (CPRM), e que drena uma área de $766,8 \mathrm{~km}^{2}$, entre as latitudes $16^{\circ} 13^{\prime}$ e $16^{\circ} 39^{\prime}$ sul e longitudes $48^{\circ} 57^{\prime}$ e $49^{\circ} 11^{\prime}$ 'oeste. O clima característico da bacia é quente e subúmido, prevalecendo inverno seco. A vegetação predominante é o cerrado, ocorrendo, também, Cerradão, mata de galeria próxima aos cursos d'água, Floresta Tropical Subcaducifólia e Caducifólia.

Na Figura 1, estão apresentadas as sedes municipais dos principais municípios inseridos na bacia. Pode-se observar que, ao sul, está localizada a cidade de Goiânia, capital do Estado, que tem no Ribeirão João Leite seu principal manancial de abastecimento, suprindo cerca de $52 \%$ da população. No entanto, outros municípios de grande expressão no cenário goiano estão diretamente ligados à bacia em estudo, como é o caso, a leste, de Anápolis, evidenciando a necessidade de uma adequada caracterização hidrológica. 


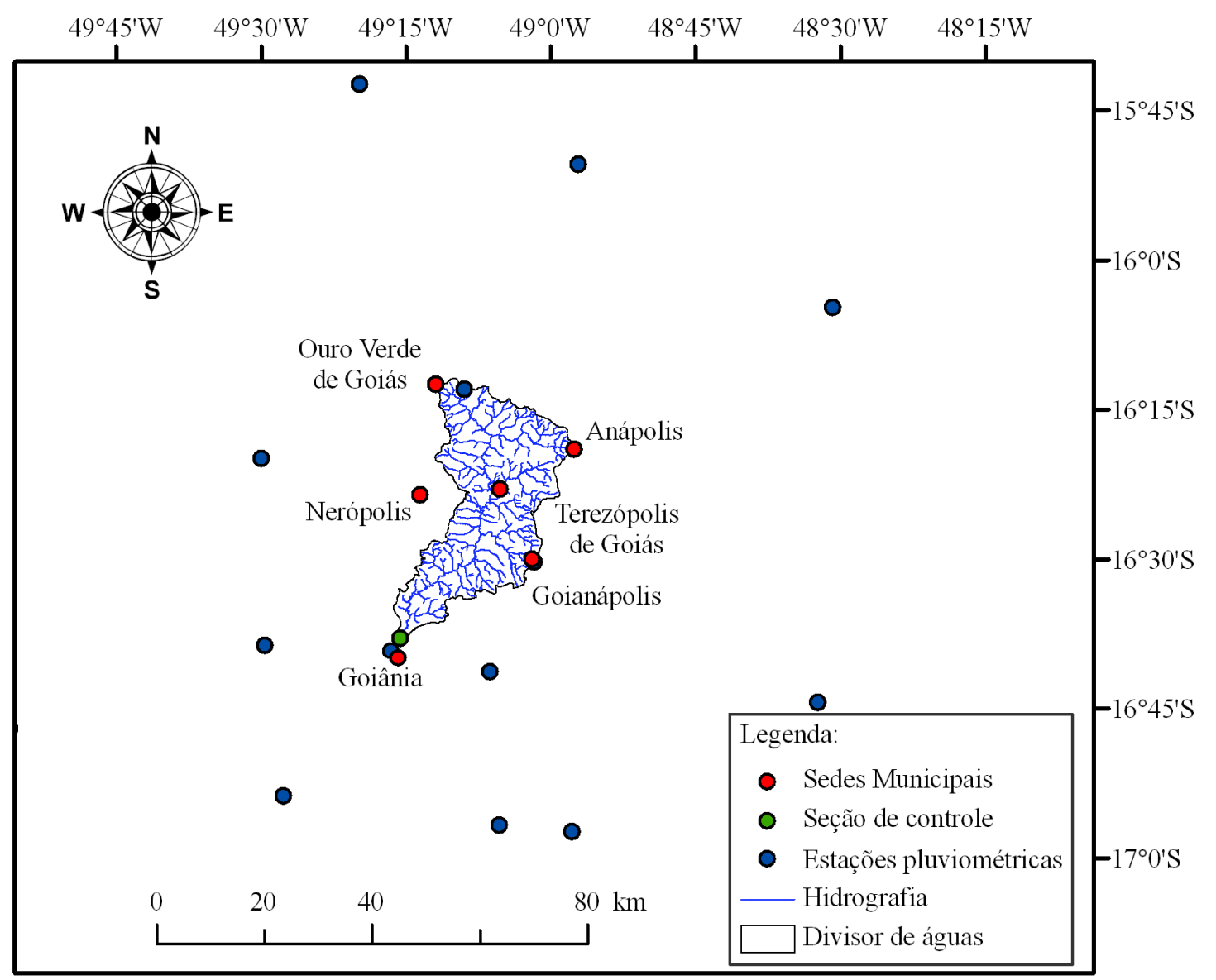

FIGURA 1. Bacia hidrográfica do Ribeirão João Leite, hidrografia e localização das sedes municipais, seção de controle e estações pluviométricas. João Leite River basin, hydrography and localization of the municipal headquarters, control section and rainfall stations.

O banco de dados consiste de séries históricas de precipitação diária disponibilizadas pelo Sistema Nacional de Informações Hidrológicas, coordenado pela Agência Nacional de Águas. A distribuição espacial das estações pluviométricas está apresentada na Figura 1.

Conforme se pode notar, algumas das estações encontram-se relativamente afastadas do perímetro da bacia hidrográfica. A justificativa para essa adoção é a escassez de informações pluviométricas na região, sendo necessário o uso de informação disponível nas redondezas. $\mathrm{Na}$ Tabela 1, estão apresentadas as principais informações das 14 estações pluviométricas empregadas neste estudo.

Inicialmente, foram estruturadas séries históricas de precipitação total mensal e anual para cada estação pluviométrica, e, a partir destas, extraíram-se valores médios para posterior análise espacial e interpolação dos dados. Devido à pequena disponibilidade de informações nas proximidades da bacia hidrográfica do Ribeirão João Leite, não foi estabelecido um período fixo para a estruturação das séries históricas, e, dessa forma, empregaram-se os dados existentes, na totalidade.

$\mathrm{Na}$ análise exploratória de dados e mapeamento da precipitação média mensal e anual na bacia hidrográfica do Ribeirão João Leite, foi empregado o programa de livre acesso GeoR (RIBEIRO JÚNIOR \& DIGGLE, 2001). Optou-se pela utilização da Projeção Universal Transversa de Mercator (UTM), com o objetivo de se obter a distância entre as estações pluviométricas em unidades métricas, ressaltando-se que o datum utilizado foi o South American 1969 (SAD69), Zona $22 \mathrm{~S}$. 
TABELA 1. Informações básicas das estações pluviométricas utilizadas. Basic information of the rainfall stations used.

\begin{tabular}{ccccc}
\hline Código & Nome & Município & Latitude & Longitude \\
\hline 1649001 & Aragoiânia & Aragoiânia & -16.9119 & -49.4522 \\
1648003 & Bela Vista de Goiás & Bela Vista de Goiás & -16.9667 & -48.9500 \\
1649002 & CCTA (EMGOPA) & Goiânia & -16.7011 & -49.0947 \\
1649003 & Fazenda Bonita de Baixo & Hidrolândia & -16.9572 & -49.0764 \\
1649004 & Goianápolis & Goianápolis & -16.5164 & -49.0203 \\
1649005 & Goiânia - Agronomia & Goiânia & -16.6667 & -49.2667 \\
1649006 & Inhumas & Inhumas & -16.3464 & -49.4942 \\
1549003 & Jaraguá & Jaraguá & -15.7197 & -49.3289 \\
1649009 & Ouro Verde de Goiás & Ouro Verde de Goiás & -16.2281 & -49.1436 \\
1649010 & Palmeiras de Goiás & Palmeiras de Goiás & -16.8031 & -49.9286 \\
1548003 & Pirenópolis & Pirenópolis & -15.8500 & -48.9500 \\
1648001 & Ponte Anápolis - Brasília & Alexânia & -16.0833 & -48.5083 \\
1649012 & Trindade & Trindade & -16.6594 & -49.4864 \\
1648002 & Vianópolis & Vianópolis & -16.7464 & -48.5247 \\
\hline
\end{tabular}

Para checar a adequabilidade dos dados estudados às técnicas geoestatísticas, realizou-se a análise exploratória de dados, conforme descrevem RIBEIRO JUNIOR \& DIGGLE (2001). Efetuaram-se gráficos da tendência espacial dos dados e box plot. O primeiro com o objetivo de verificar a existência de tendenciosidade na massa de dados, o que, caso ocorra, inviabiliza a aplicação das técnicas geoestatísticas, e o segundo com o objetivo de identificação e eliminação de valores discrepantes.

Os modelos de semivariograma ajustados ao semivariograma experimental foram o exponencial, esférico e gaussiano, enfatizando-se que, para ajuste, foi empregado o método dos mínimos quadrados ponderados. De acordo com MELLO et al. (2005), o método de ajuste dos mínimos quadrados ponderados é uma tentativa de ponderar a semivariância, uma vez que a ponderação pela variância das estimativas das semivariâncias não é conhecida, o que é obtido dividindo-se o erro quadrático médio pelo número de pares de pontos em cada distância no semivariograma.

O primeiro modelo de semivariograma ajustado foi o esférico. De acordo com VIEIRA (2000), nesse modelo, são empregados os valores do efeito pepita $\left(C_{0}\right)$ e patamar $\left(C_{0}+C_{1}\right)$. $O$ traçado desse modelo origina-se de uma reta que intercepta o eixo y em $\mathrm{C}_{0}$ e que seja tangente aos primeiros pontos próximos de $\mathrm{h}=0$, e que cruzará com o patamar a distância a' = (2/3)a.

Outra interessante característica do modelo esférico de semivariograma consiste no fato de que o mesmo é linear até aproximadamente (1/3)a, e o alcance será a = (3/2)a'.

O modelo esférico de semivariograma assume a seguinte expressão matemática:

$$
\begin{aligned}
& \gamma(\mathrm{h})=\mathrm{C}_{0}+\mathrm{C}_{1}\left[\frac{3}{2}\left(\frac{\mathrm{h}}{\mathrm{a}}\right)-\frac{1}{2}\left(\frac{\mathrm{h}}{\mathrm{a}}\right)^{3}\right] ; 0<h<a \\
& \gamma(\mathrm{h})=\mathrm{C}_{0}+\mathrm{C}_{1} ; \mathrm{h} \geq \mathrm{a}
\end{aligned}
$$

em que,

$\mathrm{C}_{0}$ - efeito pepita;

$\mathrm{C}_{0}+\mathrm{C}_{1}$ - patamar;

$\mathrm{h}$ - distância entre pares de pontos, e

a - alcance.

O segundo modelo testado foi o exponencial. De acordo com VIEIRA (2000), neste modelo, o patamar é atingido apenas assintoticamente, diferentemente do modelo esférico, no qual esse valor é atingido no valor do alcance. Cabe destacar que o alcance é determinado visualmente com a distância. O modelo exponencial assume a seguinte expressão: 


$$
\begin{aligned}
& \gamma(\mathrm{h})=\mathrm{C}_{0}+\mathrm{C}_{1}\left[1-\exp \left(-3 \frac{\mathrm{h}}{\mathrm{a}}\right)\right] ; 0<\mathrm{h}<\mathrm{a} \\
& \gamma(\mathrm{h})=\mathrm{C}_{0}+\mathrm{C}_{1} ; \mathrm{h}>\mathrm{a}
\end{aligned}
$$

O terceiro modelo de semivariograma ajustado foi o gaussiano. Segundo VIEIRA (2000), junto à origem, esse modelo apresenta uma curva parabólica, e a tangente nesse ponto é horizontal, indicando pequena variabilidade a curtas distâncias. O modelo gaussiano de semivariograma está apresentado na eq.(5):

$$
\gamma(\mathrm{h})=\mathrm{C}\left(1-\mathrm{e}^{\left(-\mathrm{h}^{2} / \mathrm{a}^{2}\right)}\right)
$$

A qualidade final dos mapas gerados por krigagem está diretamente relacionada aos parâmetros fornecidos pelo modelo de semivariograma. Para verificação do modelo de semivariograma que se sobressaiu, dentre os três estudados, estudou-se a validação cruzada (VIEIRA et al., 1981).

De acordo com VIEIRA (2000), quando se realiza a estimativa de valores em locais não medidos, ocorre certo grau de incerteza sobre as hipóteses assumidas ou, mesmo, sobre os parâmetros ajustados. Esta incerteza é devida ao erro de estimativa e insere-se a validação cruzada, como uma avaliação do erro de interpolação produzido.

A técnica da validação cruzada consiste na estimativa, empregando os parâmetros oriundos do ajuste de cada modelo de semivariograma, dos pontos que foram realmente amostrados, podendo assim comparar o valor estimado ao observado. Assim, foi estimado o erro médio (EM) produzido por cada modelo de semivariograma, para cada evento em estudo, como descrito a seguir:

$$
\begin{aligned}
& E_{j}=\left|\frac{\operatorname{Vobs}_{j}-\text { Vest }_{j}}{\operatorname{Vobs}_{j}}\right| \\
& E M=\frac{\sum_{j=1}^{n} E j}{n}
\end{aligned}
$$

em que,

$E_{j}$ - erro de estimativa em cada ponto;

Vobs $_{\mathrm{j}}$ - valor observado em cada ponto $\mathrm{j}$;

Vest $_{\mathrm{j}}$ - valor estimado em cada ponto $\mathrm{j}$, e

EM - erro médio de estimativa.

O modelo de semivariograma empregado na confecção dos mapas de precipitação média mensal e anual correspondeu ao que produziu o menor erro médio para cada evento estudado.

De acordo com MELLO et al. (2003), o equacionamento que rege o interpolador geoestatístico é dado por:

$$
\begin{aligned}
& {[\mathrm{A}]^{-1}[\mathrm{~b}]=[\lambda]} \\
& \mathrm{X}_{\text {estimado }}=\sum_{\mathrm{j}=1}^{\mathrm{n}} \lambda_{\mathrm{j}} \mathrm{X}_{\mathrm{j}}
\end{aligned}
$$

em que,

$[\mathrm{A}]^{-1}$ - matriz inversa de semivariância na vizinhança do ponto a ser estimado;

[b] - matriz de semivariância entre a vizinhança de krigagem e o ponto a ser interpolado, e

$[\lambda]$ - matriz de pesos de krigagem. 


\section{RESULTADOS E DISCUSSÃO}

Na Figura 2, apresenta-se a tendência e box plot da precipitação média mensal de janeiro, que representam o comportamento geral apresentado na análise exploratória de dados entre os diferentes eventos em estudo.

De acordo com a Figura 1, observa-se boa distribuição dos dados no sentido da longitude e da latitude, evidenciando não tendenciosidade dos mesmos, o que, de acordo com GOMES (2007), evidencia atendimento às pressuposições requeridas para a aplicação das técnicas geoestatísticas.
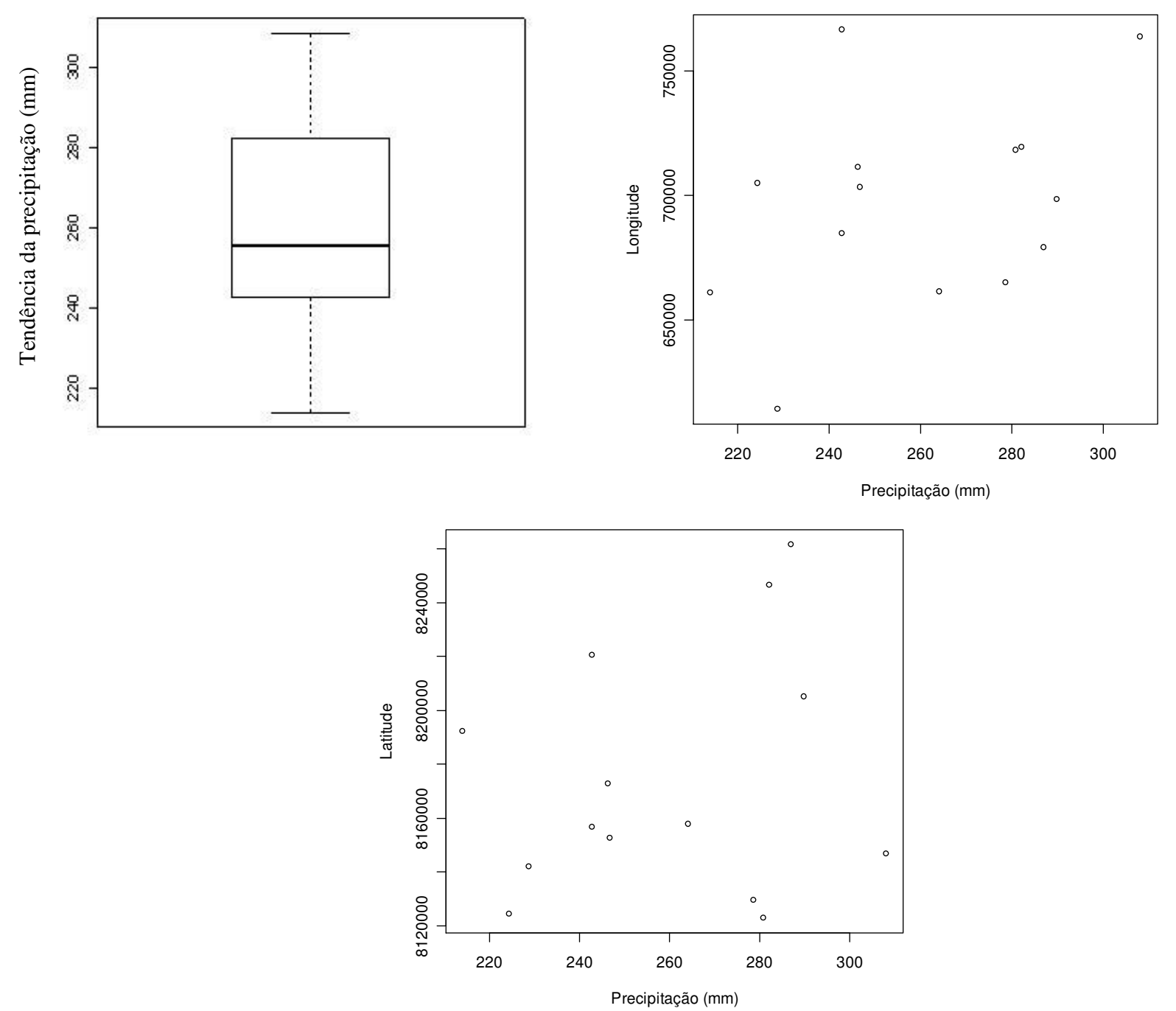

FIGURA 2. Gráficos de tendência e box plot obtidos para a precipitação média mensal de janeiro. Trend graphs and box plots obtained for the average monthly rainfall for January.

O gráfico box plot, por sua vez, permite a identificação de valores discrepantes presentes no banco de dados, os quais, de acordo com MELLO et al. (2008), podem afetar a variância aleatória, com implicação direta sobre a correlação espacial. Dessa maneira, quando identificados, os valores discrepantes foram removidos da análise.

A verificação do ajuste dos modelos de semivariograma exponencial, esférico e gaussiano aos dados de precipitação média mensal e anual, na bacia do Ribeirão João Leite, foi realizada pelo erro médio obtido por validação cruzada. Apresentam-se, na Tabela 2, os parâmetros dos modelos de semivariograma (efeito pepita, patamar e alcance) e erro médio, para os modelos de semivariograma esférico, exponencial e gaussiano ajustados pela técnica dos mínimos quadrados ponderados. 
TABELA 2. Parâmetros dos modelos de semivariograma exponencial, esférico e gaussiano ajustados por mínimos quadrados ponderados e erro médio obtido por validação cruzada. Parameters of exponential, spherical and gaussian semivariogram models adjusted by the weighted least square and mean error obtained by cross validation.

\begin{tabular}{|c|c|c|c|c|}
\hline \multicolumn{5}{|c|}{ Precipitação média mensal de janeiro } \\
\hline Modelo & Efeito Pepita & Patamar & Alcance (m) & Erro Médio (\%) \\
\hline Exponencial & 0,00 & 962,61 & $33.650,21$ & 11,38 \\
\hline Esférico & 0,00 & 901,42 & $73.284,21$ & 11,39 \\
\hline Gaussiano & 0,00 & 908,27 & $34.776,44$ & 12,45 \\
\hline \multicolumn{5}{|c|}{ Precipitação média mensal de fevereiro } \\
\hline Modelo & Efeito Pepita & Patamar & Alcance $(\mathrm{m})$ & Erro Médio (\%) \\
\hline Exponencial & 30,30 & 235,27 & $20.000,12$ & 9,55 \\
\hline Esférico & 67,58 & 151,38 & $49.950,00$ & 9,26 \\
\hline Gaussiano & 51,39 & 201,38 & $30.000,03$ & 10,39 \\
\hline \multicolumn{5}{|c|}{ Precipitação média mensal de março } \\
\hline Modelo & Efeito Pepita & Patamar & Alcance $(\mathrm{m})$ & Erro Médio (\%) \\
\hline Exponencial & 0,00 & 452,93 & $14.460,90$ & 6,79 \\
\hline Esférico & 0,00 & 455,22 & $48.351,37$ & 6,97 \\
\hline Gaussiano & 0,00 & 456,71 & $22.853,07$ & 7,11 \\
\hline \multicolumn{5}{|c|}{ Precipitação média mensal de abril } \\
\hline Modelo & Efeito Pepita & Patamar & Alcance $(\mathrm{m})$ & Erro Médio (\%) \\
\hline Exponencial & 22,36 & 298,33 & $25.000,00$ & 11,93 \\
\hline Esférico & 0,00 & 347,10 & $33.248,31$ & 15,26 \\
\hline Gaussiano & 0,00 & 347,85 & $15.090,98$ & 15,28 \\
\hline \multicolumn{5}{|c|}{ Precipitação média mensal de maio } \\
\hline Modelo & Efeito Pepita & Patamar & Alcance $(\mathrm{m})$ & Erro Médio (\%) \\
\hline Exponencial & 7,49 & 42,89 & $10.001,10$ & 15,99 \\
\hline Esférico & 18,49 & 42,59 & $29.999,96$ & 16,35 \\
\hline Gaussiano & 28,29 & 42,76 & $19.999,87$ & 16,03 \\
\hline \multicolumn{5}{|c|}{ Precipitação média mensal de junho } \\
\hline Modelo & Efeito Pepita & Patamar & Alcance $(\mathrm{m})$ & Erro Médio (\%) \\
\hline Exponencial & 1,16 & 3,38 & $50.000,00$ & 25,67 \\
\hline Esférico & 0,42 & 2,84 & $30.000,00$ & 25,71 \\
\hline Gaussiano & 2,31 & 2,95 & $50.000,00$ & 24,92 \\
\hline \multicolumn{5}{|c|}{ Precipitação média mensal de julho } \\
\hline Modelo & Efeito Pepita & Patamar & Alcance $(\mathrm{m})$ & Erro Médio $(\%)$ \\
\hline Exponencial & 0,00 & 3,73 & $23.240,01$ & 24,69 \\
\hline Esférico & 1,46 & 3,71 & $83.503,86$ & 24,36 \\
\hline Gaussiano & 1,79 & 3,70 & $40.000,00$ & 24,27 \\
\hline \multicolumn{5}{|c|}{ Precipitação média mensal de agosto } \\
\hline Modelo & Efeito Pepita & Patamar & Alcance $(\mathrm{m})$ & Erro Médio (\%) \\
\hline Exponencial $*$ & - & - & - & - \\
\hline Esférico & 2,40 & 16,12 & $63.826,80$ & 121,54 \\
\hline Gaussiano* & - & - & - & - \\
\hline \multicolumn{5}{|c|}{ Precipitação média mensal de setembro } \\
\hline Modelo & Efeito Pepita & Patamar & Alcance $(\mathrm{m})$ & Erro Médio (\%) \\
\hline Exponencial * & - & - & - & - \\
\hline Esférico & 1,54 & 58,36 & $25.200,02$ & 14,96 \\
\hline Gaussiano & 3,87 & 60,01 & $24.999,36$ & 18,25 \\
\hline \multicolumn{5}{|c|}{ Precipitação média mensal de outubro } \\
\hline Modelo & Efeito Pepita & Patamar & Alcance $(\mathrm{m})$ & Erro Médio (\%) \\
\hline Exponencial * & - & - & - & - \\
\hline Esférico & 0,87 & 202,70 & $34.999,98$ & 13,14 \\
\hline Gaussiano * & - & - & - & - \\
\hline \multicolumn{5}{|c|}{ Precipitação média mensal de novembro } \\
\hline Modelo & Efeito Pepita & Patamar & Alcance $(\mathrm{m})$ & Erro Médio $(\%)$ \\
\hline Exponencial & 0,00 & 407,79 & $12.843,82$ & 7,64 \\
\hline Esférico & 119,88 & 401,91 & $39.863,06$ & 7,60 \\
\hline Gaussiano & 271,35 & 408,69 & $29.991,84$ & 7,73 \\
\hline \multicolumn{5}{|c|}{ Precipitação média mensal de dezembro } \\
\hline Modelo & Efeito Pepita & Patamar & Alcance $(\mathrm{m})$ & Erro Médio $(\%)$ \\
\hline Exponencial & 0,00 & 913,01 & $30.751,59$ & 7,98 \\
\hline Esférico & 0,00 & 861,41 & $69.567,63$ & 8,49 \\
\hline Gaussiano & 0,00 & 882,02 & $34.865,10$ & 8,22 \\
\hline \multicolumn{5}{|c|}{ Precipitação média Anual } \\
\hline Modelo & Efeito Pepita & Patamar & Alcance $(\mathrm{m})$ & Erro Médio (\%) \\
\hline Exponencial & $1.781,36$ & $15.838,63$ & $36.342,30$ & 7,65 \\
\hline Esférico & $2.899,66$ & $14.485,04$ & $79.833,66$ & 7,67 \\
\hline Gaussiano & $5.850,36$ & $14.854,46$ & $44.708,37$ & 7,72 \\
\hline
\end{tabular}


O conhecimento do alcance do semivariograma é fundamental para a interpretação dos resultados obtidos pelas técnicas geoestatísticas e, em termos práticos, representa a distância limite da dependência espacial. Estes variaram de aproximadamente 10 a $83 \mathrm{~km}$, permitindo a constatação de uma abrangente estrutura de dependência espacial da precipitação média mensal e anual na bacia hidrográfica do Ribeirão João Leite, o que indica, de acordo com MELLO et al. (2005), que o mapeamento por técnicas geoestatísticas pode propiciar bons resultados.

O erro médio geral obtido por validação cruzada, considerando os três modelos de semivariograma analisados, variou significativamente. Foram encontrados menores erros médios nos meses de março, novembro, precipitação anual, dezembro, fevereiro e janeiro, com valores de 6,$79 ; 7,60 ; 7,65 ; 7,98 ; 9,26$ e 11,38\%, respectivamente. Em contrapartida, os maiores erros médios ocorreram nos meses de agosto, junho, julho, maio, setembro, outubro e abril, com valores de 121,$54 ; 24,92 ; 24,27 ; 15,99 ; 14,96 ; 13,14$ e $11,93 \%$.

A magnitude dos erros encontrados para a precipitação média mensal e anual na bacia do Ribeirão João Leite enfatiza o elevado potencial da krigagem no mapeamento desta variável, uma vez que, em se tratando do mapeamento de dados climáticos, são esperados erros elevados, em virtude da variabilidade natural do clima na Terra.

Pode-se constatar que os maiores erros de interpolação foram obtidos para a estação seca do ano, o que pode ser observado na Figura 3. Concomitantemente, nos meses de agosto a outubro, foi notada dificuldade de ajuste de alguns modelos de semivariogramas, com efeito pepita puro em cinco situações, notadamente para o modelo exponencial em agosto, setembro e outubro e para o modelo gaussiano em agosto e outubro. Essa ocorrência pode ser certamente atribuída aos baixos índices pluviométricos predominantes durante a estação seca na bacia do Ribeirão João Leite, muitas vezes aproximando-se de zero e, assim, dificultando o estabelecimento da dependência espacial.

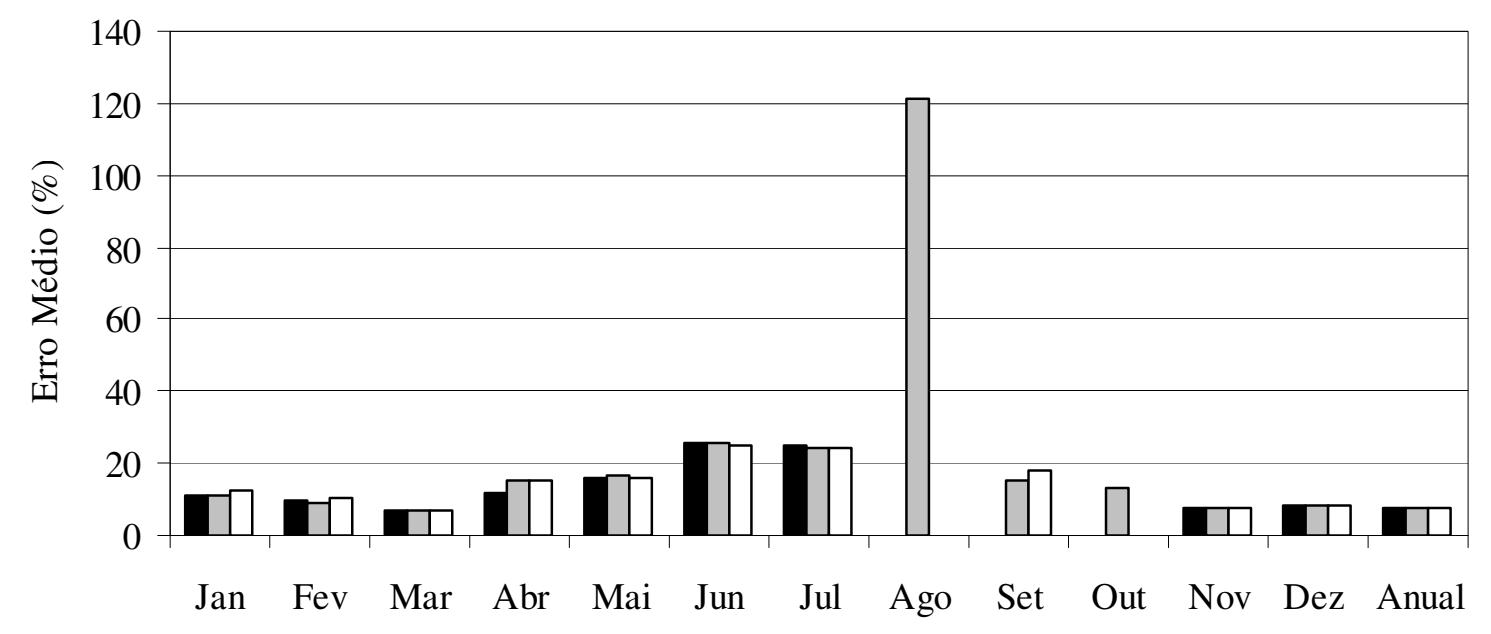

Exponencial $\square$ Esférico $\square$ Gaussiano

FIGURA 3. Erro médio obtido por validação cruzada para os modelos de semivariograma exponencial, esférico e gaussiano, na espacialização da precipitação média mensal e anual, na bacia do Ribeirão João Leite - GO. Average error obtained by crossvalidation for the exponential, spherical and gaussian semivariogram models in the spatial distribution of monthly and annual average rainfall in the Joao Leite basin, GO.

A interpretação do erro médio de ajuste calculado pela validação cruzada revelou menores erros produzidos pelo modelo exponencial nos meses de janeiro, março, abril, maio e anual; pelo modelo esférico, nos meses de fevereiro, agosto, setembro, outubro, novembro e dezembro; e pelo modelo gaussiano, nos meses de junho e julho. Desta forma, foi obtido melhor desempenho do 
modelo exponencial de semivariograma em seis das 13 situações estudadas, e dos modelos esférico e gaussiano em cinco e duas situações, respectivamente. Estes resultados estão em consonância com os obtidos por CARVALHO \& ASSAD (2005) e MELLO et al. (2008), os quais avaliaram o desempenho de diferentes modelos de semivariograma no mapeamento da precipitação, nos Estados de São Paulo e Minas Gerais, respectivamente.

Contudo, fica explícita a necessidade de estudo do ajuste de diferentes modelos de semivariograma ao semivariograma experimental, visto que, embora o modelo exponencial tenha-se sobressaído em maior número de eventos, não foi possível ajustá-lo aos dados dos meses de agosto, setembro e outubro, nos quais se obteve ajuste pelo modelo esférico.

$\mathrm{Na}$ Figura 4, apresentam-se os modelos de semivariograma ajustados aos dados de precipitação média mensal de janeiro, que evidencia a distribuição média observada dentre os distintos eventos estudados. Observa-se, nesta Figura, bom ajuste dos modelos teóricos ao semivariograma experimental, mostrando que podem ser obtidos resultados satisfatórios no mapeamento dos dados em estudo pelas técnicas geoestatísticas.

janeiro

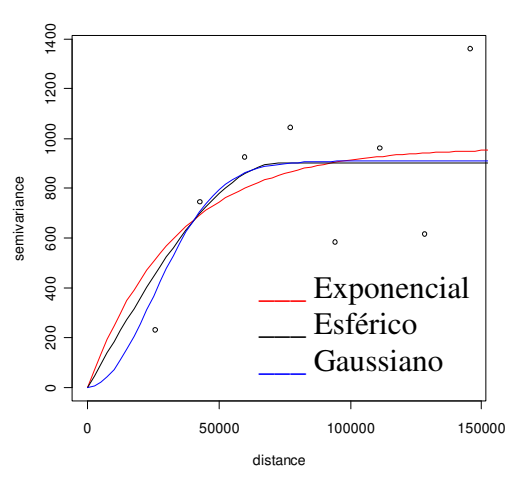

FIGURA 4. Modelos de semivariograma ajustados ao semivariograma experimental. Semivariogram models adjusted to the experimental semivariogram.

O mapeamento da precipitação foi conduzido utilizando o modelo de semivariograma que produziu o menor erro médio para cada evento em estudo. Na Figura 5, constam os mapas de precipitação média mensal e anual obtidos por krigagem para a bacia hidrográfica do Ribeirão João Leite. Os mapas estão na Projeção Universal Transversa de Mercator (UTM) e datum South American 1969 (SAD69), zona 22 sul. As unidades constantes nas legendas representam a lâmina de precipitação média para cada período, em $\mathrm{mm}$, sendo que os menores valores adquirem a coloração vermelha, seguindo para a coloração amarela com seu incremento.

Pode-se observar concentração das chuvas entre outubro e março, onde as lâminas precipitadas apresentaram valores médios mensais acima de $200 \mathrm{~mm}$. O auge do período chuvoso, com médias mensais variando de 255 a $265 \mathrm{~mm}$ e de 250 a $290 \mathrm{~mm}$ ao longo da bacia, ocorreu em dezembro e janeiro, respectivamente, cabendo destacar que nesses meses foram registrados 17,46 e $17,04 \%$ da precipitação média anual na bacia, respectivamente.

Nos demais meses do período que concentrou o maior percentual de chuvas na bacia do Ribeirão João Leite (outubro, novembro, fevereiro e março), observaram-se percentuais de 9,18; 13,$98 ; 13,98$ e $14,16 \%$, totalizando, conjuntamente a dezembro e janeiro, cerca de $85,8 \%$ da precipitação média anual e que, em termos de lâmina, representa cerca de $1.308 \mathrm{~mm}$.

A distribuição espacial das chuvas nos meses de maior precipitação seguiu um padrão de maiores lâminas ao norte da bacia, próximo à estação pluviométrica de Ouro Verde de Goiás, tendo sido observadas, nos meses de janeiro, fevereiro e março, lâminas médias alcançando os 290; 220 e $250 \mathrm{~mm}$, respectivamente. 


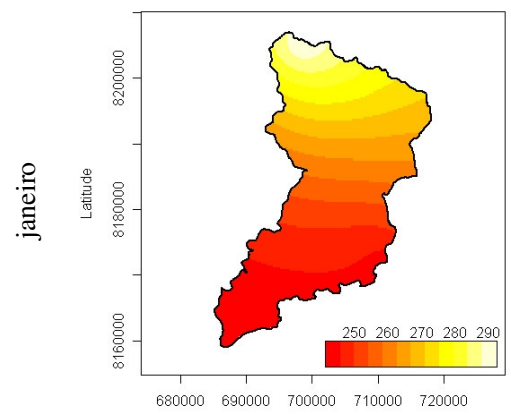

Longitude

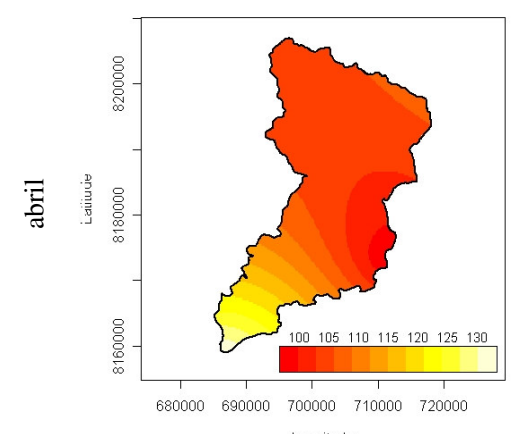

Longitude

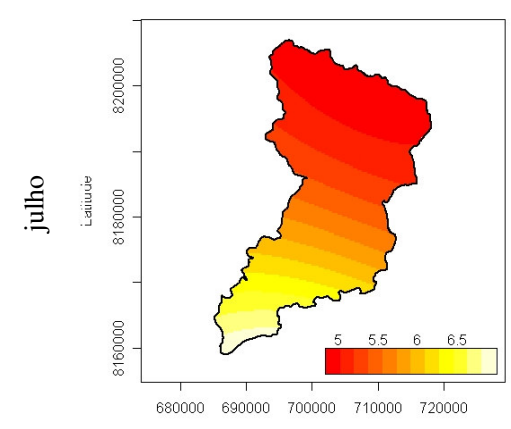

Longitude

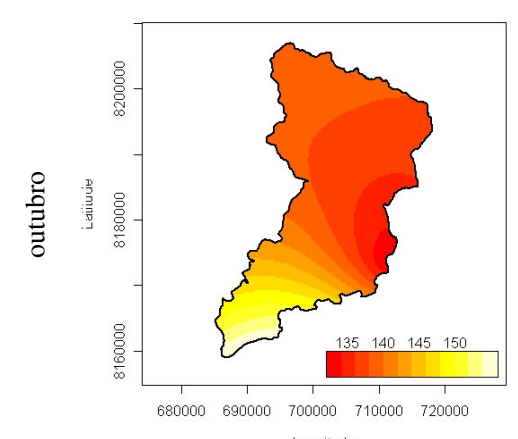

Longitude

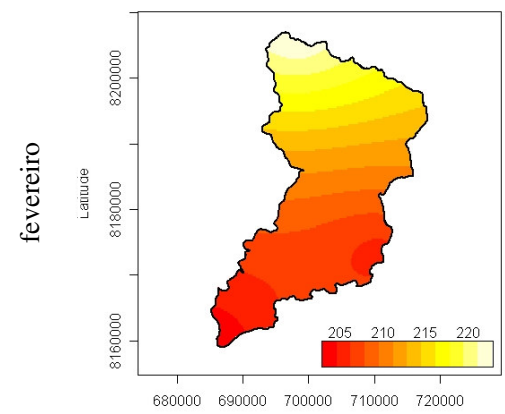

Longitude

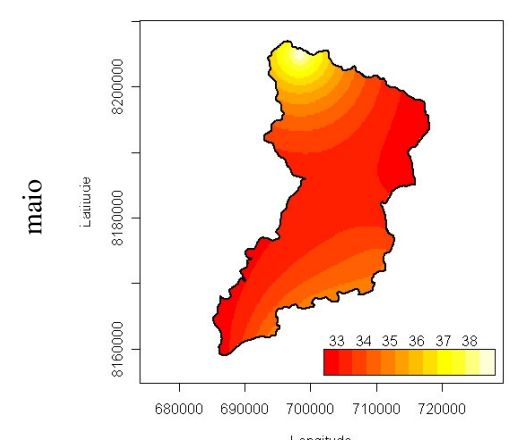

Longitude

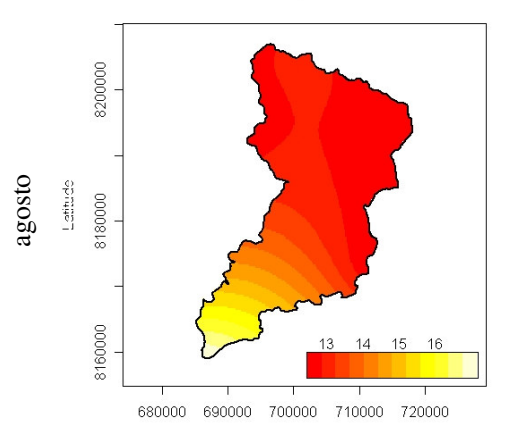

Longitude
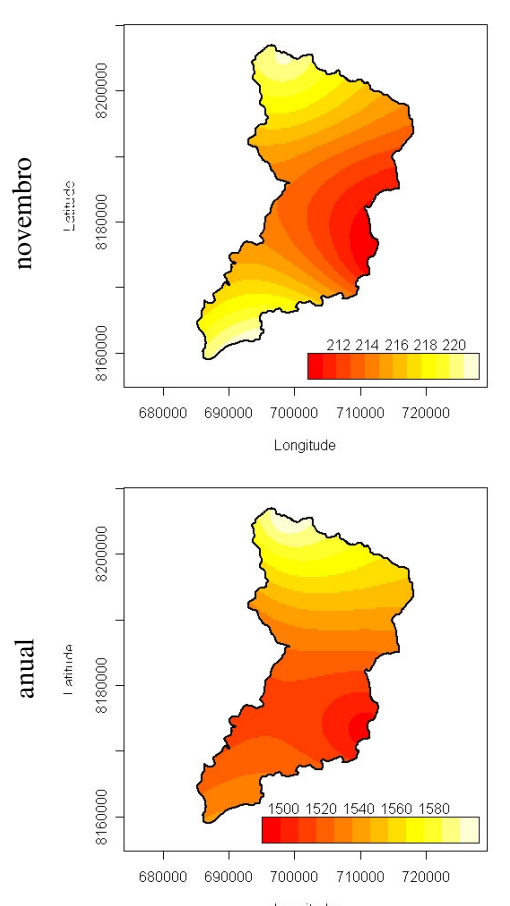

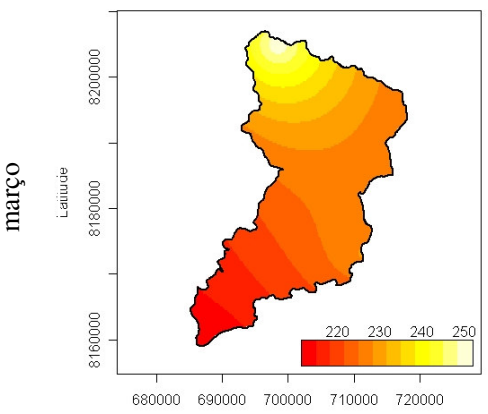

Longitude

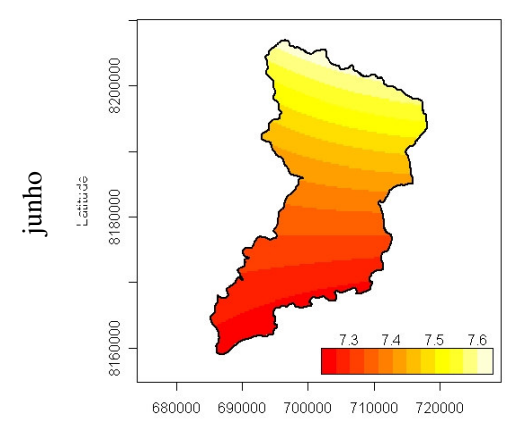

Longitude

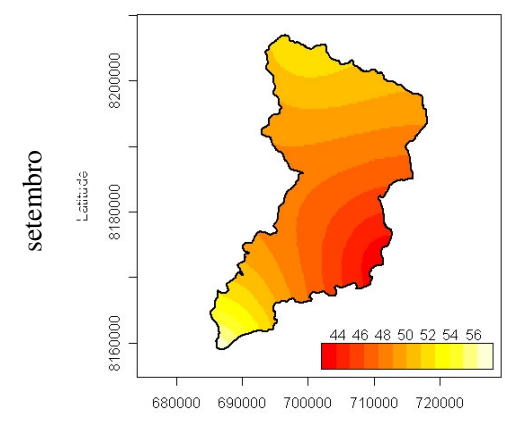

Longitude

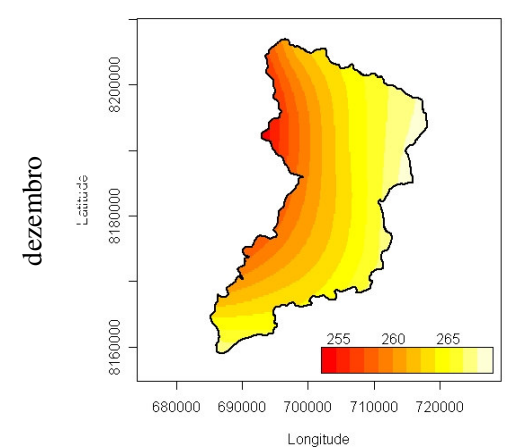

FIGURA 5. Mapas de precipitação média mensal e anual obtidos por krigagem para a bacia hidrográfica do Ribeirão João Leite - GO. Maps of average monthly and annual precipitation obtained by Kriging for João Leite River basin, GO. 
Já nos meses de outubro, novembro e dezembro, pode-se observar um padrão diferenciado na distribuição espacial da precipitação. Em outubro, a região que concentrou as maiores lâminas foi a sul, próxima à estação pluviométrica de Goiânia - Agronomia, enquanto em novembro o mesmo se deu nos extremos norte e sul da bacia e, em dezembro, a leste, influenciado pela estação pluviométrica de Goianápolis.

Pode-se verificar, também, que a amplitude de variação da precipitação média mensal ao longo da bacia foi pequena, sendo de aproximadamente $40 \mathrm{~mm}$ no auge do período chuvoso e chegando a poucos milímetros durante os meses mais secos do ano. Este comportamento está certamente relacionado à pequena extensão da bacia, que ocupa área de $766,8 \mathrm{~km}^{2}$, e a grande abrangência da estrutura de variabilidade espacial apontada pela análise geoestatística.

Durante os meses de menor precipitação na bacia do João Leite, que se estenderam de abril a setembro, a precipitação média mensal variou de 0,39 a $7,22 \%$ da precipitação média anual, em julho e abril, respectivamente. Fica evidenciado também, durante esse espaço de tempo, que contempla meio ano, um período bastante seco, no qual a média precipitada correspondeu a 14,20\% da precipitação média anual. Cabe destacar, também, que nos meses de maio, junho, agosto e setembro, a média precipitada mensalmente tomou percentuais de 2,$11 ; 0,52 ; 0,80$ e $3,16 \%$, respectivamente.

Nos meses de abril, julho e agosto, a região que concentrou os maiores registros de chuva se deu ao sul da bacia, nas proximidades da estação pluviométrica Goiânia - Agronomia, com lâminas atingindo os 130; 6,5 e $16 \mathrm{~mm}$, respectivamente. Nos referidos meses, a porção norte da bacia hidrográfica concentrou as menores lâminas, nas proximidades da estação de Ouro Verde de Goiás, chegando a 100; 5 e $13 \mathrm{~mm}$, respectivamente.

Já nos meses de maio e junho, foi observado um padrão diferenciado na distribuição espacial das chuvas, em comparação aos demais meses do período seco, ocorrendo maiores índices ao norte, e que decresceram no sentido sul da bacia. Nesses meses, a precipitação média mensal variou de 33 a $38 \mathrm{~mm}$ e de 7,3 a 7,6 mm, respectivamente, caminhando ao auge do período seco, que se deu em julho, onde foram estimadas lâminas variando de $5 \mathrm{a} 6,5 \mathrm{~mm}$. Contudo, em setembro, nos extremos norte e sul da bacia, foram observadas maiores lâminas, chegando acerca de $56 \mathrm{~mm}$, reservando à faixa leste da bacia, nas proximidades da estação de Goianápolis, as menores lâminas, da ordem de $44 \mathrm{~mm}$.

Visualizando-se o mapa de precipitação média anual nota-se uma faixa de menores precipitações médias anuais, da ordem de $1.500 \mathrm{~mm}$, na faixa central da bacia, próxima à estação de Goianápolis. Pode-se notar também gradiente crescente nas direções norte e sul, onde são alcançadas lâminas de 1.580 e $1.520 \mathrm{~mm}$, respectivamente. Cabe destacar que, novamente, foi encontrada uma pequena amplitude de variação das lâminas médias ao longo da bacia hidrográfica, que foi de 1.500 a $1.580 \mathrm{~mm}$.

\section{CONCLUSÕES}

O modelo exponencial ajustado pelo método dos mínimos quadrados apresentou melhor ajuste, o que permite sugeri-lo como sendo o mais adequado na aplicação das técnicas geoestatísticas no mapeamento da precipitação média mensal e anual na bacia hidrográfica do Ribeirão João Leite.

Pode-se constatar que a interpolação geoestatística (krigagem) obteve um bom desempenho na espacialização da precipitação média mensal e anual, com base no pequeno erro médio gerado pela validação cruzada.

A análise do padrão temporal do regime pluvial mostrou dois períodos característicos, um chuvoso, de outubro a março, no qual ocorrem cerca de $85,8 \%$ da precipitação anual, com aproximadamente $35 \%$ concentrado nos meses de dezembro e janeiro, e outro seco, de abril a setembro, respondendo por $14,2 \%$ da precipitação anual. 
O comportamento espacial da precipitação pluvial mostrou pequena variabilidade dos índices pluviométricos mensais ao longo da bacia hidrográfica, respondendo por cerca de $40 \mathrm{~mm}$ no auge do período chuvoso e chegando a poucos milímetros durante os meses mais secos do ano.

\section{REFERÊNCIAS}

BERTONI, J.C.; TUCCI, C.E. Precipitação. In: TUCCI, C.E.M. (Org.). Hidrologia: ciência e aplicação. 2.ed. Porto Alegre: ABRH/Editora UFRGS, 2001. p.177-231.

CARVALHO, J.R. de; ASSAD, E.D. Análise espacial da precipitação pluviométrica no estado de São Paulo: Comparação de métodos de interpolação. Engenharia Agrícola, Jaboticabal, v.25, n.2, p.377-384, 2005.

CECÍLIO, R.A.; PRUSKI, F.F. Interpolação dos parâmetros da equação de chuvas intensas com uso do inverso de potências da distância. Revista Brasileira de Engenharia Agrícola e Ambiental, Campina Grande, v.7, n.3, p.501-504, 2003.

GOMES, N.M.; SILVA, A.M. da; MELLO, C.R. de; FARIA, M.A. de; OLIVEIRA, P.M. Métodos de ajuste e modelos de semivariograma aplicados ao estudo da variabilidade espacial de atributos físico-hídricos do solo. Revista Brasileira de Ciência do Solo, Campinas, v.31, n.3, 2007.

JUNQUEIRA JÚNIOR, J A.; SILVA, A.M. da; MELLO, C.R. de; PINTO, D.B.F. Continuidade espacial de atributos físico-hídricos do solo em sub-bacia hidrográfica de cabeceira. Ciência e Agrotecnologia, Lavras, v.32, p.914-922, 2008.

MELLO, C.R. de.; LIMA, J.M.; SILVA, A.M.; MELLO, J.M.; SILVA, M.S. Krigagem e inverso do quadrado da distância para interpolação dos parâmetros da equação de chuvas intensas. Revista Brasileira de Ciência do Solo, Campinas, v.27, n.5, p.925-933, 2003.

MELLO, C.R. de; VIOLA, M.R.; MELLO, J.M. de; SILVA, A.M. da. Continuidade espacial de chuvas intensas no Estado de Minas Gerais. Ciência Agrotécnica, v.32, n.2, p.532-539, 2008.

MELLO, J.M.; BATISTA, J.L.F.; RIBEIRO JÚNIOR, P.J.; OLIVEIRA, M.S. Ajuste e seleção de modelos espaciais de semivariograma visando à estimativa volumétrica de Eucaliptus grandis. Scientia Forestalis, Piracicaba, v.1, n.1, p.25-37, 2005.

MONTEBELLER, C.A.; CEDDIALL, M.B.; CARVALHO, D.F. de; SIDNEY, R.V.; FRANCO, E.M. Variabilidade espacial do potencial erosivo das chuvas no Estado do Rio de Janeiro. Engenharia Agrícola, Jaboticabal, v.27, n.2, p.426-435, 2007.

REIS, M.H.; GRIEBELER, N.P.; SARMENTO, P.H.L.; OLIVEIRA, L.F.C.; OLIVEIRA, J.M. Espacialização de dados de precipitação e avaliação de interpoladores para projetos de drenagem agrícola no Estado de Goiás e Distrito Federal. In: SIMPÓSIO BRASILEIRO DE

SENSORIAMENTO REMOTO, 12., 2005, Goiânia. Anais...

RIBEIRO JÚNIOR, P.J.; DIGGLE, P.P. GeoR: a package for geoestatistical analysis. $R-N e w s$, Rochester, v.I, n.2, p.15-18, 2001

SOUZA, Z.M. de; MARTINS FILHO, M.V.; MARQUES JÚNIOR, J.; PEREIRA, G.T. Variabilidade espacial de fatores de erosão em Latossolo Vermelho eutroférrico sob cultivo de cana-de-açúcar. Engenharia Agrícola, Jaboticabal, v.25, n.1, p.105-114, 2005.

VIEIRA, S. R. Geoestatística em estudos de variabilidade espacial do solo: Tópicos em ciência do solo. Viçosa - MG: Sociedade Brasileira de Ciência do Solo, 2000. p.1-54.

VIEIRA, S.R.; HATFIELD, T.L.; NIELSEN, D.R.; BIGGAR, J.W. Spatial variability of fieldmeasured infiltration rate. Soil Science Society of America Journal, Madison, v.45, p.1.040-1.048, 1981. 